\title{
Aphid polyphenisms: trans-generational developmental regulation through viviparity
}

\author{
Kota Ogawa * and Toru Miura \\ Laboratory of Ecological Genetics, Graduate School of Environmental Science, Hokkaido University, Sapporo, Japan
}

\section{Edited by:}

Masataka G. Suzuki, The University of Tokyo, Japan

\section{Reviewed by:}

Harunobu Shibao, The University of

Tokyo, Japan

Dayalan G. Srinivasan, Rowan

University, USA

*Correspondence:

Kota Ogawa, Laboratory of

Ecological Genetics, Graduate

School of Environmental Science,

Hokkaido University, Sapporo,

Hokkaido 060-0810, Japan.

e-mail:k-lepi83@ees.hokudai.ac.jp
Polyphenism, in which multiple discrete phenotypes develop from a single genotype, is considered to have contributed to the evolutionary success of aphids. Of the various polyphenisms observed in the complex life cycle of aphids, the reproductive and wing polyphenisms seen in most aphid species are conspicuous. In reproductive polyphenism, the reproductive modes can change between viviparous parthenogenesis and sexual reproduction in response to the photoperiod. Under short-day conditions in autumn, sexual morphs (males and oviparous females) are produced parthenogenetically. Winged polyphenism is observed in viviparous generations during summer, when winged or wingless (flightless) aphids are produced depending on a variety of environmental conditions (e.g., density, predators). Here, we review the physiological mechanisms underlying reproductive and wing polyphenism in aphids. In reproductive polyphenism, morph determination (male, oviparous or viviparous female) within mother aphids is regulated by juvenile hormone $(\mathrm{JH})$ titers in the mothers. In wing polyphenism, although $\mathrm{JH}$ is considered to play an important role in phenotype determination (winged or wingless), the role is still controversial. In both cases, the acquisition of viviparity in Aphididae is considered to be the basis for maternal regulation of these polyphenisms, and through which environmental cues can be transferred to developing embryos through the physiological state of the mother. Although the mechanisms by which mothers alter the developmental programs of their progeny have not yet been clarified, continued developments in molecular biology will likely unravel these questions.

Keywords: Acyrthosiphon pisum, aphid, hemimetabolous insect, hormonal regulation, maternal signal, reproductive polyphenism, viviparity, wing polyphenism

\section{INTRODUCTION}

In an attempt to understand the basis for the morphological diversity observed in organisms, studies focusing on developmental regulation and the evolution thereof have become a central theme in modern biology. In some organisms, the surrounding environment can switch the developmental fate as well as act on phenotypes as selective pressures. "Phenotypic plasticity" refers to the emergence of phenotypic variation in a developing organism in response to changes in environmental conditions (Hall, 1999; West-Eberhard, 2003). An extreme example of phenotypic plasticity is "polyphenism," in which discrete alternative phenotypes are produced from the same genotype in response to extrinsic factors (Nijhout, 1999, 2003). How a single genotype can produce such markedly different phenotypes is an important question in developmental biology. In polyphenism, developmental trajectories for alternative phenotypes can be illustrated using forked pathways with a developmental switch leading to alternative phenotypes (Nijhout, 1999). In many cases, the developmental switches are regulated by physiological factors, like hormones, that mediate environmental (or genetic) factors and differential developmental mechanisms (Nijhout, 2003; WestEberhard, 2003). In all known cases of polyphenisms in insects, the switching mechanisms of developmental pathways leading to alternative phenotypes are mediated by either the timing of hormone secretion, the timing of a hormone sensitive period, or the threshold of hormone sensitivity (Nijhout, 1999).

Aphids, which are small insects belonging to the family Aphididae in the order Hemiptera (sucking bugs), are major agricultural pests that damage plants through ingesting plant sap for nutrition, and by transmitting viral diseases in many crops (Dixon, 1998). Of the approximately 5000 species of aphids that have been described to date (Aphid Species File, Version 5.0/5.0, http://aphid.speciesfile.org/), all employ apomictic parthenogenesis (clonal or asexual reproduction) as their primary mode of reproduction (Simon et al., 2002).

In addition to wing (winged/macropterous, brachypterous or wingless) and reproductive (sexual reproduction or parthenogenesis) polymorphisms (Miyazaki, 1987; Dixon, 1998; Le Trionnaire et al., 2008; Brisson, 2010), aphids also exhibit body-color and caste polymorphisms (Aoki, 1977; Miyazaki, 1987; Fukatsu, 2010; Tsuchida et al., 2010), most of which are also recognized as being polyphenisms. Many aphid species show wing polyphenism in which winged morphs appear in response to changes in environmental factors in order to facilitate migration to new host plants or habitats (Dixon, 1998; Braendle et al., 2006; Brisson, 2010). Reproductive polyphenism, in which sexual reproduction and parthenogenesis are switched depending on seasonal conditions, is also exhibited by many aphid lineages (Le Trionnaire 
et al., 2008; Davis, 2012), and in social aphids, caste polyphenism results in the production of soldier aphids which appear to defend their gall (nest) [Aoki, 1977; Hattori et al., 2013; reviewed in Itô (1989); Stern and Foster (1996); Shibao et al. (2010)]. Since these flexible phenotypes of aphids should contribute to the remarkable adaptations seen in aphids (Dixon, 1998), the characteristics of these diverse and plastic phenotypes are important in the areas of ecology, evolutionary biology, and developmental biology. Here we review the biological basis underlying polyphenism in aphids, with a particular focus on reproductive and wing polyphenisms, and consider the various developmental mechanisms underlying phenotypic changes in response to different environmental conditions.

\section{REPRODUCTIVE POLYPHENISM IN APHIDS ADAPTIVE SIGNIFICANCE OF THE REPRODUCTIVE POLYPHENISM}

Traditionally referred to as the "two-fold cost of sex," asexual reproduction is generally considered to be useful for increasing population size at twice the rate that is possible by sexual reproduction as no males are produced (Williams, 1975; Maynard Smith, 1978). In addition, sexual reproduction may incur other costs, such as finding mates, which are avoided in animals that reproduce asexually. It may therefore not be surprising that reproduction by parthenogenesis has been acquired independently, and often secondarily, in numerous organisms (Schön et al., 2009).

Aphids exhibit both sexual and asexual reproduction depending on the season. The typical annual life cycle of aphids consists of cyclical parthenogenesis which consists of a succession of parthenogenetic generations (approximately 10-30 generations in typical species) followed by a single sexual one (Moran, 1992; Simon et al., 2002; Figure 1). Many aphids with typical life cycles overwinter by employing frost-resistant, diapausing eggs, from which a female called a "fundatrix" or "stem mother" hatches in spring. These females are asexual and responsible for producing "viviparous females," which also reproduce asexually until autumn. In late autumn, males and oviparous females, which are produced by parthenogenetic viviparous females, mate and lay overwintering eggs (Figure 1). Parthenogenesis in aphids is classified as apomixes, i.e., parthenogenesis in which the eggs do not undergo meiosis (Blackman, 1987). Consequently, except for spontaneous mutation and chromosome elimination in males (see Chromosomal Sex Determination System in Reproductive Polyphenism for a description of chromosome elimination in males), individuals within a single strain (lineage) are genetically identical (Blackman, 1987; Sloane et al., 2001; Davis, 2012). In the parthenogenetic oocytes of aphids, new centrosomes and microtubule-based asters, which are necessary for spindle formation in the first mitotic division, are organized spontaneously (Riparbelli et al., 2005); however, the centrosome is acquired from the male gamete during fertilization in sexually reproducing organisms (including sexual generation in aphids) (Riparbelli et al., 2005; Rodrigues-Martins et al., 2007).

In the case of reproductive polyphenism, the induction of the sexual generation (males and oviparous females) and the subsequent production of eggs capable of surviving cold temperatures are a series of short-term adaptive responses to environmental cues indicating the onset of winter (Dixon, 1998; Simon et al.,

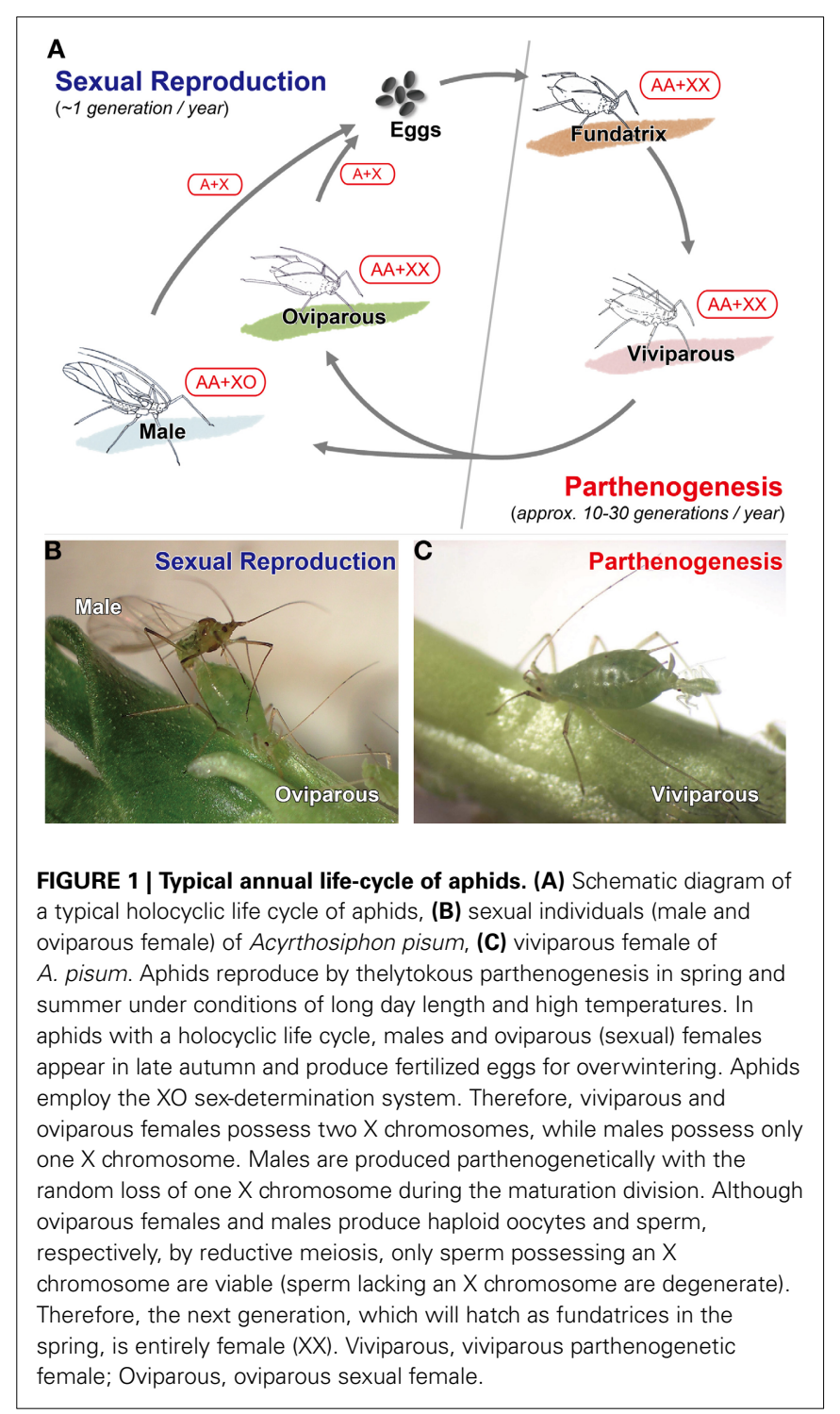

2002, 2010). Although cyclical parthenogenesis is observed in all subfamilies in Aphididae (Simon et al., 2002; Figure 2), strictly asexual generations have only been described in approximately $3 \%$ of all aphid species (e.g., Myzus ascalonicus and Toxoptera citricidus) (Moran, 1992; Simon et al., 2002). In other words, the sexual generation may have been secondarily lost in these entirely asexual species. Moreover, approximately $30 \%$ of described aphid species include both cyclical-parthenogenetic and asexual clones (Moran, 1992; Dixon, 1998; Simon et al., 2002). Such strictly asexual species (or clones) tend to be distributed in low-latitude regions, suggesting that the sexual reproduction in aphids is an adaptation to severe winters, and that the parthenogenesis occurs in areas in which nymphal or adult aphids can overwinter (Simon et al., 1996, 2002, 2010; Rispe and Pierre, 1998; Rispe et al., 1998; Dixon, 1998). In other words, cyclical parthenogenesis in aphids has evolved in order to facilitate asexual viviparous reproduction as well as by overwintering by diapausing eggs (Simon et al., 1996, 2002, 2010; Rispe and Pierre, 1998; Rispe et al., 1998; 


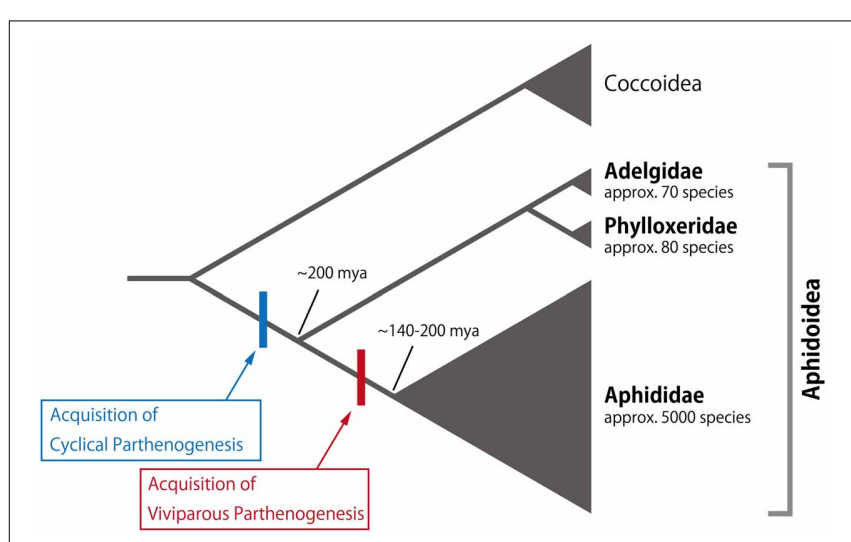

FIGURE 2 | Phylogeny of aphids and sister groups. Cyclical parthenogenesis and viviparity are serially acquired in the Aphidoidea lineage. Extant species numbers in the families are indicated below each family name. Considerable diversification is seen in Aphididae, showing both of cyclical parthenogenesis and viviparity. The phylogeny and extant species numbers are based on Davis (2012) and Aphid Species File (Version 5.0/5.0, http://aphid.speciesfile.org/), respectively.

Dixon, 1998). However, the above explanation cannot be applied to all species and groups. For example, in Nipponaphis monzeni, the sexual generation appears in early spring and laid fertilized eggs hatch in May of the same year (Kurosu and Aoki, 2009). Moreover, species belonging to Adelgidae and Phylloxeridae are capable of producing eggs through parthenogenesis, i.e., by oviparous parthenogenesis, indicating that sexual reproduction is not necessarily required for egg production (Granett et al., 2001; Havill and Foottit, 2007; Figure 2).

\section{ENVIRONMENTAL CUES RESPONSIBLE FOR SWITCHING REPRODUCTIVE MODES}

In many aphid species, short-day length and low temperature are major environmental cues for inducing the production of a sexual generation. The influence of photoperiod on the reproductive modes of aphids was first reported by Marcovitch (Marcovitch, 1923, 1924), who showed that sexual individuals of Aphis forbesi emerged in response to a short day length (Marcovitch, 1923); interestingly, that study was also the first report of photoperiodic induction in animals. In particular, in Megoura viciae, oviparous (sexual) females are produced when the day length is less than $14.5 \mathrm{~h}$ at $15^{\circ} \mathrm{C}$; however, this response disappears above $23^{\circ} \mathrm{C}$ (Lees, 1959, 1963). Moreover, in Acyrthosiphon pisum which has a critical photoperiod of $13-14 \mathrm{~h}$ for the induction of sexual individuals (Lamb and Pointing, 1972), the critical photoperiod in the North American population increases by approximately $35 \mathrm{~min}$ for every $1^{\circ} \mathrm{N}$ latitude (Smith and MacKay, 1990). Aphids that produce sexual individuals perceive increases in night length (scotoperiod) from late summer to autumn (Hardie, 1990). In contrast, in some aphid species, sexual reproduction occurs in response to physiological changes of the host plants. For example, sexual morphs of Aphis farinosa and Dysaphis devecta are produced in response to cessation of host plant shoot growth (Forrest, 1970; Dixon, 1998). Furthermore, subterranean species living under constant darkness at relatively constant temperature also produce sexual morphs when the host plants become dormant (Dixon, 1998). However, it is not yet known which cues associated with the cessation of host-plant growth trigger these changes in aphids.

\section{CHROMOSOMAL SEX DETERMINATION SYSTEM IN REPRODUCTIVE POLYPHENISM}

Biologists have studied sex determination in aphids with complex life cycles for more than 100 years (e.g., Stevens, 1905, 1906, 1910; Morgan, 1909a,b). In addition to apomictic parthenogenesis, aphids employ the XO sex-determination system (Stevens, 1905, 1906; Wilson et al., 1997), which means that sexual females are genetically identical to their asexual mothers and, like their mothers, possess two $\mathrm{X}$ chromosomes. In contrast, males, which are hemizygous for the $\mathrm{X}$ chromosome $(\mathrm{XO})$, are produced parthenogenetically with the random loss of one $\mathrm{X}$ chromosome during maturation division, which is modified meiosis without chromosomal reduction (Stevens, 1910; Morgan, 1915; Orlando, 1974, 1983; Blackman and Hales, 1986; Wilson et al., 1997; Figure 1). These sexual females and males then mate after producing haploid oocytes and sperm by the same reductive meiosis step employed by "normal" sexual organisms, but recombination then typically only occurs in the females (Blackman, 1976). In the males, only sperm possessing an $\mathrm{X}$ chromosome are viable, while sperm without $\mathrm{X}$ chromosome (O sperm) are degenerate (Stevens, 1905, 1906; Blackman, 1985). Consequently, the next generation, which hatches in spring, consists entirely of females (XX) (Figure 1). With the exception of several minor differences, this type of chromosomal manner is also found in adelgids and phylloxerans (Morgan, 1906, 1908, 1909a,b, 1912, 1915; Steffan, 1970; Havill and Foottit, 2007).

\section{WING POLYPHENISM IN APHIDS ADAPTIVE SIGNIFICANCE OF WING POLYPHENISM}

The ability of insects to fly, which is considered to have been acquired only once in the class Insecta, has contributed enormously to their diversity and evolutionary success (Roff, 1990; Dudley, 2002). However, despite enabling insects to seek out new habitats, mates, and food resources, the capacity for flight is associated with considerable costs for insects (Harrison, 1980; Roff, 1990). Consequently, numerous insect species have secondarily lost the ability to fly in favor of allocating energy toward traits such as fecundity, longevity and weapons for intra- and interspecific competition (Harrison, 1980; Roff, 1990; Roff and Fairbairn, 1991). In other words, as a result of tradeoffs between flying ability and other traits, wing polymorphisms and/or flightless phenotypes (c.f. brachypterous or apterous/wingless) have evolved in numerous insect taxa (Wagner and Liebherr, 1992; Zera and Denno, 1997).

Wing polymorphism in aphids is associated with their complex life cycles (Brisson, 2010). In several aphid lineages (e.g., tribe Macrosiphini), wing polymorphisms have been attributed to both genetic and environmental factors, sometimes even within a single species (see Wing Polyphenism and Genetic Wing Polymorphism for details) (Smith and MacKay, 1989; Caillaud et al., 2002; Braendle et al., 2005a,b, 2006; Brisson, 2010). Viviparous females typically exhibit wing polyphenism and develop into winged 
or wingless morphs (Heie, 1987; Miyazaki, 1987; Dixon, 1998; Braendle et al., 2006; Brisson, 2010). In exceptional cases in the Drepanosiphinae and Phyllaphidinae, only oviparous females exhibit the wingless phenotype, while the other morphs are always winged (Heie, 1987; Dixon, 1998). In Myzocallis kuricola, though all viviparous females possess wings, dimorphism in the form of macropterous and brachypterous forms are known (Moritsu, 1983).

The winged and wingless phenotypes in aphids differ in a wide variety of morphological, physiological, life-history and behavioral characteristics. In addition to having wings and functional flight muscles, the fully winged morphs exhibit more extensive sclerotization of the head and thorax, more developed compound eyes, ocelli, longer antennae, more rhinaria, and occasionally larger siphunculi and cauda (Kalmus, 1945; Kring, 1977; Kawada, 1987; Miyazaki, 1987; Ishikawa and Miura, 2007; Ogawa et al., 2012). Most of these differences reflect the different lifestyles of the two morphs. For example, the winged morphs are equipped with an elaborate sensory system for flight and host plant location, and they are also more resistant to starvation (Tsuji and Kawada, 1987b; Hazell et al., 2005). In addition, the morphological differences between the winged and wingless phenotypes are usually correlated with differences in the ecological significance of each morph. Winged phenotypes typically have longer nymphal development periods, a longer pre-reproductive adult period, a longer reproductive period, lower fecundity, and prolonged longevity (Noda, 1960; MacKay and Wellington, 1975; Campbell and Mackauer, 1977; Tsuji and Kawada, 1987b; Tsumuki et al., 1990; Ogawa et al., 2012).

\section{ENVIRONMENTAL CUES RESPONSIBLE FOR SWITCHING BETWEEN WING TYPES}

A number of environmental cues affecting the dispersal phenotypes (winged/macropterous or wingless/brachypterous) of aphids have been identified, especially in viviparous females (Hille Ris Lambers, 1966; Lees, 1966; Mittler and Sutherland, 1969; Müller et al., 2001). As in other insects, like locusts, density-dependent regulation of alternative dispersal phenotypes is widespread in aphids. Specifically, high-density triggers wing formation in many species (Johnson, 1965; Lees, 1967; Sutherland, 1969a; Shaw, 1970). Although the receptors of tactile stimuli have not yet been identified, the increase in tactile stimulation between individuals is considered to be the cue of high-density conditions (Johnson, 1965). In some species, antennae are considered to play an important role in the perception of tactile signals (Johnson, 1965; Lees, 1967; Sutherland, 1969a). The presence of natural enemies can also affect morph determination. In Acyrthosiphon pisum, winged-morph production is increased under conditions of high predation (Dixon and Agarwala, 1999; Weisser et al., 1999; Sloggett and Weisser, 2002; Kunert and Weisser, 2003). Two factors are considered to contribute to wing morph induction: the release of alarm pheromone, and the increase in tactile stimulation associated with avoidance behavior (Kunert et al., 2005, 2008). Conversely, the presence of ants that protect aphids from predators can inhibit both the induction of winged (dispersal) individuals and development of the flight apparatus (wings and flight muscles)
(El-Ziady and Kennedy, 1956; Kleinjan and Mittler, 1975; Yao, 2012).

Traditionally, host plant quality (i.e., nutrition) was considered to be a key factor in morph determination (e.g., Sutherland, 1969b). However, Müller et al. (2001) showed that the findings of more than half of 38 studies on 12 different aphid species did not support the traditional hypothesis. In many of these earlier studies, morph determination appeared to depend on aphid density, although the density was considered to reflect the nutritive condition of the host plant (Müller et al., 2001). Nevertheless, in a few species, low nutrition alone can induce winged-morph production (Müller et al., 2001).

Furthermore, other factors, such as parasitoids, pathogens of aphids or plants, temperature, photoperiod, are also known to affect wing induction (White, 1946; Kenten, 1955; Johnson and Birks, 1960; Lees, 1966; Schaefers and Judge, 1971; Dixon, 1998; Müller et al., 2001; Leonardo and Mondor, 2006; Hatano et al., 2012). By responding to several of these stimuli rather than one, it is possible that aphids can track changes in environmental conditions more accurately. Indeed, it is likely that the multiple environmental stimuli that act on the central nervous system affect the physiology of the aphids, inducing wingless phenotypes possessing high fecundity under favorable conditions, and when conditions become unfavorable, allowing aphids to switch to the winged phenotypes to disperse to new habitats. In some aphids, such as Megoura crassicauda and Acyrthosiphon pisum, these environmental stimuli are processed by the mother aphid and the morphs of her resulting progeny are determined maternally or grandmaternally (Müller et al., 2001; Ishikawa and Miura, 2013). Thus, in these aphids, winged morphs are induced trans-generationally and if these aphid nymphs are crowded, the proportion of the winged adults in the same generation does not differ from other groups that have been reared under low-density conditions (Müller et al., 2001). However, in other aphid species, such as Aphis craccivora (Johnson, 1965), Myzus persicae (Sutherland and Mittler, 1971) and Therioaphis maculata (Toba et al., 1967), high density stimulus to younger nymphs can induce the winged morph in the same generation (Hille Ris Lambers, 1966; Lees, 1966; Müller et al., 2001). These findings suggest that the mechanisms underlying the developmental determination of wing polyphenism are specified (or optimized) in each aphid species or within groups.

\section{WING POLYPHENISM AND GENETIC WING POLYMORPHISM}

In the pea aphid, Acyrthosiphon pisum, several regulatory mechanisms are known to be involved in the wing polymorphisms/polyphenisms associated with the different reproductive modes observed in the annual life cycle of the aphid (Dixon, 1998; Braendle et al., 2006; Brisson, 2010). As in other aphid species, unfavorable environmental conditions can induce the expression of the winged phenotype in viviparous female generations (Lees, 1966; Sutherland, 1969a). On the other hand, wing polymorphism in males has a genetic basis and the aphicarus (api) locus on the $\mathrm{X}$-chromosome is responsible for the determination of wing types (winged or wingless) (Smith and MacKay, 1989; Caillaud et al., 2002; Braendle et al., 2005a,b). However, all oviparous 
females and fundatrices are monomorphic wingless (Miyazaki, 1987; Brisson, 2010).

Recent studies have shown that the development/degeneration processes of the flight apparatus (wings and flight muscle) differ among morphs of Acyrthosiphon pisum (Ogawa et al., 2012; Ogawa and Miura, 2013). Studies on female wing polyphenism showed that the first-instar nymphs of wingless viviparous females possess wing and flight-muscle primordia, which then degenerate during postembryonic development (Tsuji and Kawada, 1987a; Ishikawa et al., 2008). However, in the case of male wing polymorphism, the flight muscles of wingless morphs are developed and differentiated, even though they appear to be non-functional (Ogawa et al., 2012; Figure 3). Furthermore, the flight-apparatus primordia are not formed during embryogenesis or postembryonic development in oviparous females, or during postembryonic development in fundatrices (Ogawa and Miura, 2013; Figure 3). These findings suggest that although male and female winged forms both share similar developmental patterns, the regulation of flight apparatus development differs among wingless forms, which evolved secondarily from winged phenotypes. In other words, the diversity of derived developmental pathways in Acyrthosiphon pisum is considered to reflect the ecological traits of the respective morphs. For example, the pathway involved in primordia formation and context-dependent degeneration in viviparous females may facilitate a rapid response to environmental cues (Ogawa and Miura, 2013). Developmental regulation of the flight apparatus in Acyrthosiphon pisum is well suited for comparing and contrasting the developmental basis of genetically determined and environmentally induced phenotypes, as well as for considering how the evolutionary transition between genetic polymorphism, polyphenism, and monomorphism may have occurred.

\section{PHYSIOLOGICAL BASIS FOR APHID POLYPHENISM}

Endocrine factors, i.e., hormones have long been implicated in the control of polyphenism, either through spatial and temporal patterns of hormone levels or through the expression patterns of related factors in different tissues (Nijhout, 1999). For example, in the cricket genus Gryllus, a decrease in juvenile hormone (JH) esterase levels slows down $\mathrm{JH}$ degradation in the last nymphal instar. The relative increase in the JH titer compared to the ecdysteroid titer induces the development of short-winged morphs rather than of long-winged morphs (Zera et al., 1989; Zera, 2003). Similarly, in the honeybee Apis mellifera, workers feed those larvae designated to be queens relatively more royal jelly protein, which activates an endocrine response that elevates $\mathrm{JH}$ levels and eventually results in the production of queens rather than workers [reviewed in Hartfelder and Engels (1998)].

\section{PHYSIOLOGICAL BASIS FOR SWITCHING REPRODUCTIVE MODES}

Many aphids can accurately perceive scotoperiod length, and a specific number of constant dark- and light-cycles can induce sexual forms (Hardie, 1990). The perception of scotoperiod presumably employs an internal clock and a counting mechanism (Hardie and Nunes, 2001). The photoperiodic signal is detected directly by the brain through the cuticle or via the visual system (Lees, 1964; Le Trionnaire et al., 2009). It has been demonstrated

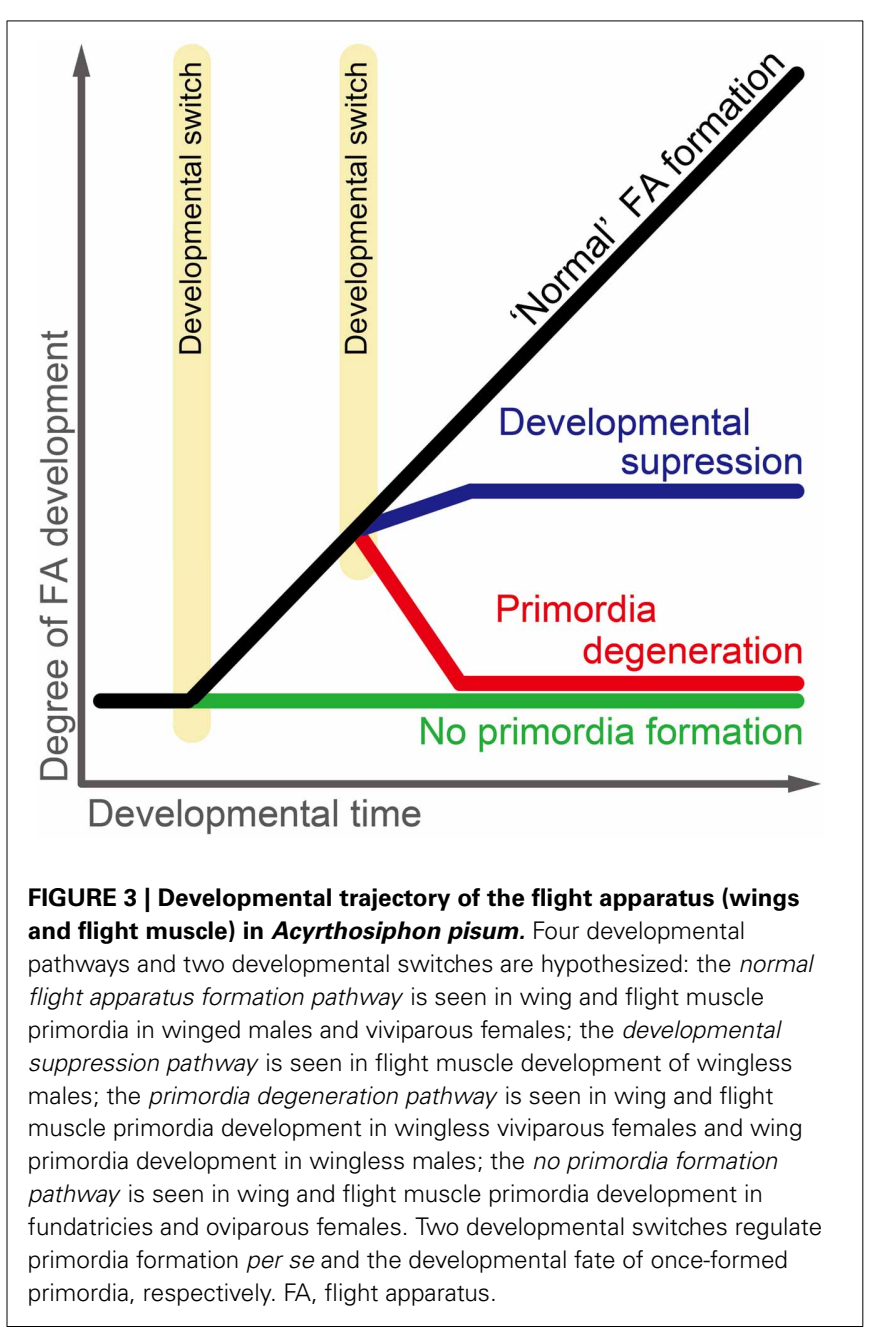

experimentally that a group of neurosecretory cells (NSC) located in the dorsoanterior region of the protocerebrum (pars intercerebralis) was required for the perception of photoperiodic signals (Lees, 1964; Steel and Lees, 1977; Gao et al., 1999). Impairment of neurosecretory cells by cauterization inhibited the production of parthenogenetic morphs, even under short-night (long-day) conditions (Lees, 1964; Steel and Lees, 1977). Thus, it appears that sexual morphs are produced irrespective of photoperiod conditions when neurosecretory cells do not function, and physiological changes mediated by neurosecretory cells are required for reproduction of asexual morphs.

Although the capacity for parthenogenesis under short-night conditions would have been acquired by the ability of cells to secrete molecules that change the developmental fate of the oocytes, the transfer mechanism of the photoperiodic signal to the ovaries for orientation of the reproductive pathways (asexual or sexual) has not yet been resolved. However, it seems likely that such a transfer mechanism involves the endocrine system, e.g., melatonin or JH, at some stage (Corbitt and Hardie, 1985; Hardie et al., 1985; Gao and Hardie, 1997; Ishikawa et al., 2012). In particular, the JHIII titer in Acyrthosiphon pisum was shown to be lower in aphids producing sexual morphs under short-day 
conditions than in aphids producing parthenogenetic morphs under long-day conditions (Ishikawa et al., 2012). Furthermore, gene expression levels of $\mathrm{JH}$ esterase, which is responsible for JH degradation, were significantly higher in aphids reared under short-day conditions (Ishikawa et al., 2012). This suggests that up-regulation of the $\mathrm{JH}$ degradation pathway is responsible for the lower JHIII titer in aphids exposed to short days, leading to the production of sexual morphs. Global transcriptomic approaches have also detected changes in the expression of genes correlate with the response to photoperiodic cues (Le Trionnaire et al., 2009; Huybrechts et al., 2010). In particular, the expression of two genes in the insulin pathway is affected by decrease in day length: a transcript, probably coding for an insulin receptor, is downregulated, and an enzyme transcript involved in insulin degradation is up-regulated (Le Trionnaire et al., 2009). This studies suggest that down-regulation of the insulin pathway occurred in the pea aphids reared under long-night (short-day) conditions (Le Trionnaire et al., 2009). In Drosophila melanogaster, the regulation of insulin pathway is correlated with the $\mathrm{JH}$ pathway ( $\mathrm{Tu}$ et al., 2005). Furthermore, in Culex pipiens, the insulin pathway regulates diapause, which is also induced by decrease in daylength and changes in the relative concentration of JH (Sim and Denlinger, 2008). Similarly, the insulin pathway might contribute to the developmental regulation of reproductive polyphenism in aphids as an upstream regulator of the $\mathrm{JH}$ pathway (Huybrechts et al., 2010).

\section{PHYSIOLOGICAL BASIS FOR SWITCHING WING TYPES}

In the wing polyphenism of aphids, hormones are strong candidates for mediating the developmental responses to environmental cues. Although $\mathrm{JH}$ was previously considered to be a strong candidate for such a role, studies attempting to inhibit the production of winged progeny by manipulating $\mathrm{JH}$ titers have produced inconsistent results [reviewed in Braendle et al. (2006)]. In some aphid species, application of precocene II (PII), a plantderived compound that is assumed to affect $\mathrm{JH}$ production, to mothers has been shown to induce the production of winged progeny [reviewed in Braendle et al. (2006)]. In other words, a decrease in the $\mathrm{JH}$ titer after PII application was considered to have induced winged progeny; however, subsequent studies have shown that this inducing effect was not mediated by $\mathrm{JH}$. First, although PII has been shown to induce winged progeny in Acyrthosiphon pisum, PII was unable to induce precocious development, which is the classic benchmark for demonstrating the effect of decreased JH titers (Hardie et al., 1996). Secondly, coapplication with $\mathrm{JH}$ fails to reverse the wing-inducing effects of PII (Gao and Hardie, 1996). Thus, the mode of PII action on wing induction is not mediated by $\mathrm{JH}$ and remains to be clarified.

Although JH has been shown to affect the development of the flight apparatus (Ishikawa et al., 2013), JH titers in parthenogenetic females subjected to high and low density conditions were similar (Schwartzberg et al., 2008), implying that $\mathrm{JH}$ is not responsible for fate determination leading to winged or wingless morphs. Alternatively, tissue-specific regulation downstream of the $\mathrm{JH}$ action may be important for fate determination, as well as the cases in other insects (Pursley et al., 2000; Parthasarathy et al., 2008). To clarify the relationship between $\mathrm{JH}$ and fate determination, comparative analyses across aphid species exhibiting differences in the induction mechanisms associated with wing development would be required, as the regulatory mechanisms may not be conserved completely among species.

\section{TRANS-GENERATIONAL TRANSFER OF MATERNAL SIGNALS THROUGH VIVIPARITY}

Since the developmental fates of the various morphs are often determined prenatally, particularly insofar as reproductive and wing polyphenisms are concerned, the acquisition of viviparity by the Aphididae lineage likely constitutes the preadaptive basis for trans-generational regulation of these polyphenisms. The development of viviparity in aphids is considered to be an evolutionary innovation that may have contributed to the diversity and abundance of the Aphididae, which currently contains approximately 5000 species (thirty times more than the total number of species in Adelgidae and Phylloxeridae) (Davis, 2012; Figure 2). In viviparous parthenogenesis, the granddaughters of a female aphid (mother) are already developing within the daughter embryos of the mother. This nesting structure consisting of multiple generations has a high demographic potential, as considerable numbers of offspring can be produced asexually under favorable conditions. This type of viviparity in aphids is referred to as pseudoplacental viviparity.

In pseudoplacental viviparity, nutritional input is provided by maternal hemolymph through the cells of the ovariole sheath, a unicellular epithelial layer that surrounds each ovariole [Couchman and King, 1980; reviewed in Bermingham and Wilkinson (2009)]. In addition to there being little or no yolk in the viviparous oocytes and embryos, there is also no chorion, probably because in addition to being dispensable, an eggshell could interfere with maternal provisioning of developing embryos (Blackman, 1987; Bermingham and Wilkinson, 2009). This close and continued association creates a unique opportunity for the mother to convey information about surrounding environments directly to her daughters (and granddaughters in some situations) before they are even born (Figure 4). In the case of oviparity, which is the method most widely found in insects, in order to convey environmental information transgenerationally, maternally-synthesized transmissible signals (e.g., mRNA) must be transferred to the eggs at the time of oviposition, which means that any such transfer of environmental information can only occur at the beginning of development. Furthermore, since developing embryos cannot move freely and do not have fullydifferentiated and functional receptive organs, their perception of extrinsic factors might be limited. Taken together, the potential for environmental responsiveness associated with oviparity is likely to be lower than that associated with viviparity. Thus, the evolution of viviparity in aphids might provide the basis for rapid and flexible developmental switching.

Furthermore, viviparity might facilitate long-term environmental monitoring mediated by maternal or grand-maternal signals, as well as more reliable tracking (or prediction) of environmental conditions. For example, young clones founded by fundatrices produce no sexual individuals, even if they are reared under short-day low-temperature conditions (Lees, 1960; 


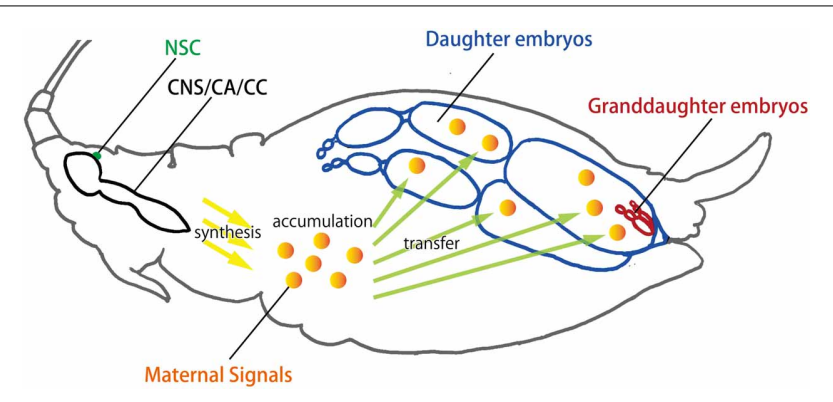

FIGURE 4 | Transgenerational transfer of maternal signals in viviparous aphids. Viviparity in aphids is classified as pseudoplacental viviparity. Interestingly, the granddaughters of a female aphid (viviparous mother) are already developing within the daughters inside the mother. This telescoping association creates a unique opportunity for the mother to convey environmental information directly to her daughters (and granddaughters in some situations) via her hemolymph through the ovariole sheath. The multi-step events leading to the production of different aphid polyphenisms are hypothesized in this reproductive unit: (1) the mother perceives environmental information and integrates the information, probably via the NSC or CNS; (2) the mother converts the stimuli into a transmissible signal, probably in the $\mathrm{CA}$ or $\mathrm{CC}$; $(3)$ this signal is transmitted to the daughter embryos developing in the ovarioles of the mother; (4) the daughter embryos respond to the signal. CA, corpora allata; CC, corpora cardiaca; CNS, central nerve system; NSC, neuro secretory cells.

Dixon, 1972). This reproductive control is known as interval timer' and considered to be an adaptation to avoid the unexpected production of a sexual generation under short-day low-temperature condition in early spring (Lees, 1960; Dixon, 1972, 1998). Furthermore, winged adults and progeny descended from winged mothers rarely, if ever, produce winged offspring (Sutherland, 1970; Mackay and Wellington, 1977). However, wingless progeny derived from wingless mothers respond strongly to wing-inducing stimuli (Mackay and Wellington, 1977; MacKay and Lamb, 1979). These findings suggest that, in aphids, environmental information perceived by ancestors can be passed down through generations, and also that developmental fate must be determined following the integration of such successive information.

\section{PERSPECTIVE: APHIDS AS A MODEL OF POLYPHENISM}

As described above, the distinct polyphenisms observed in aphids could serve as model for the study of polyphenism in animals generally. Since the genome of Acyrthosiphon pisum has been sequenced is now open to public (International Aphid Genomics Consortium, 2010), A. pisum is the strongest candidate for such a model aphid species. Compared to other insect or arthropod genomes, the genome of Acyrthosiphon pisum is distinctive for several reasons (International Aphid Genomics Consortium, 2010). The genome is large (approximately $520 \mathrm{Mbp}$ ) and so is the number of predicted genes; more than 35,000 genes have been predicted based on sequence homology, EST, or RNAseq data. The large number of genes is considered to be due to a large number of gene duplications (International Aphid Genomics Consortium, 2010). Specifically, 2459 gene families have undergone aphid lineage-specific duplications and more than 5 paralogs are contained in many families. Moreover, these paralogs account for almost half of the total number of aphid genes. The number of lineage-specific duplicated genes is greater than that of any other sequenced insect genome, although the genome of Daphnia pulex, which, like A. pisum, also exhibits extensive polyphenisms as well as has lineage-specific duplications (Colbourne et al., 2011). It is thus possible that multiple developmental pathways might be maintained in a single genome set as a result of these gene duplications. These aphid-specific gene duplications may also play a key role in polyphenic developmental regulation; for example, differential expression of diverged paralogs may occur in response to particular environmental conditions (Shigenobu et al., 2010). More precisely, environmentaldependent alternative expression of paralogous genes, which are newly acquired or which have lost a critical function, may determine the conclusive phenotype. This hypothesis is supported by numerous studies on differential paralogous gene expression between different morphs or between mothers that produce different morphs (e.g., Ramos et al., 2003; Cortés et al., 2008; Le Trionnaire et al., 2009; Brisson et al., 2010; Srinivasan et al., 2010; Lu et al., 2011; Price et al., 2011; Ishikawa et al., 2012; Duncan et al., 2013; Bickel et al., 2013).

Recently, epigenetic modifications to DNAs and to histones (e.g., methylation and acetylation) are considered to have contributed to the regulation of plastic developments in animals and plants (Bollati and Baccarelli, 2010; Blomen and Boonstra, 2011; Lyko and Maleszka, 2011; Feil and Fraga, 2012; Cortessis et al., 2012). In aphids, a functional DNA methylation system, functional small RNA system, and expanded sets of chromatin modifying genes were discovered as the factors related to the epigenetic developmental regulation [reviewed in Srinivasan and Brisson (2012)]. Interestingly, in A. pisum, a DNA region in a gene coding $\mathrm{JH}$ binding protein in winged viviparous females was highly methylated relative to wingless viviparous females (Walsh et al., 2010), suggesting the existence of regulatory cross-talk between physiological and epigenetic mechanisms. Therefore, future analyses of the coordinated regulation by epigenetic (e.g., methylation) and physiological (e.g., JH) systems will provide us new insight of the polyphenic development in aphids, in addition to the genomic regulation.

In addition to the availability of genome information, the ease with which the aphids can be reared and morphs can be induced by conditional manipulation is also an advantage of using A. pisum as a model organism. For example, induction systems for all $A$. pisum morphs have been established in our laboratory (Ishikawa et al., 2012; Ogawa et al., 2012; Ogawa and Miura, 2013). Furthermore, since all female phenotypes within the same strain are genetically identical, the influence of genetic variation can be ignored (Ogawa et al., 2012; Ogawa and Miura, 2013). To maximize the potential benefits associated with these characteristics, well-designed experiments that consider the unique developmental characteristics of aphid are required. For example, because aphids can respond to multiple environmental stimuli and transfer these environmental signals trans-generationally, pre-induction conditions in which aphids are reared under stable conditions through multiple generations before the onset of experiments is important. In our experience, 
such pre-induction has a marked improvement on experimental repeatability (Ishikawa et al., 2012). Moreover, strain selection is also important as induction rates have been observed to differ among strains, in both reproductive (Smith and MacKay, 1990; Hazell et al., 2005; Ogawa et al., 2012) and wing polyphenism (Lamb and MacKay, 1979).

On the other hand, A. pisum is an agricultural pest and techniques for gene function analysis in this species are not advanced. Sharing the same strains among members of the aphid research community would be straightforward due to their clonal reproduction. However, the importation of aphid strains is difficult and cumbersome procedures are required due to restrictions based on measures such as the International Plant Protection Convention (IPPC). From a molecular biological perspective, experimental procedures for techniques such as gene knockout/knockdown analysis in aphids have not yet been widely established; however, some studies on gene silencing by RNA interference (RNAi) have been published (Mutti et al., 2006; Jaubert-Possamai et al., 2007; Pitino et al., 2011; Mao and Zeng, 2012). Recently, genomeediting methods using zinc-finger nucleases (ZFNs) or transcription activator-like effector nucleases (TALEN) have been used extensively for genetic knockout in non-model insects (e.g., Watanabe et al., 2012). These techniques should also be applied to investigations on aphid polyphenism, providing new insights into the mechanisms and evolutionary processes associated with this phenomenon.

\section{ACKNOWLEDGMENTS}

We are grateful to Drs. Ken-ichi Moto, Shinji Nagata, Masataka G. Suzuki, and jozef Vanden Broeck for invitation to the research topic "Adaptive responses to environments through physiological regulations in insects" in Frontiers in Physiology and for giving the opportunity to write this paper. We also express our appreciation to Hiroki Gotoh for providing the literature informations. This work was supported in part by the Ministry of a Grant-in-Aid for Young Scientists (No. 21677001 to Kota Ogawa) and by Grantin-Aid for Scientific Research (A) (No. 25251041 to Toru Miura) from the Japan Society for the Promotion of Science (JSPS).

\section{REFERENCES}

Aoki, S. (1977). Colophina clematis (Homoptera, Pemphigidae), an aphid species with soldiers. Kontyû 45, 276-282.

Bermingham, J., and Wilkinson, T. L. (2009). Embryo nutrition in parthenogenetic viviparous aphids. Physiol. Entomol. 34, 103-109. doi: 10.1111/j.13653032.2008.00669.x

Bickel, R. D., Cleveland, H. C., Barkas, J., Jeschke, C. C., Raz, A. A., Stern, D. L., et al. (2013). The pea aphid uses a version of the terminal system during oviparous, but not viviparous, development. Evodevo 4, 10. doi: 10.1186/20419139-4-10.

Blackman, R. L. (1976). Cytogenetics of two species of Euceraphis (Homoptera, Aphididae). Chromosoma 56, 393-408. doi: 10.1007/BF00292958

Blackman, R. L. (1985). Spermatogenesis in the aphid Amphorophora tuberculata (Homoptera, Aphididae). Chromosoma 92, 357-362. doi: 10.1007/BF00327467

Blackman, R. L. (1987). "Reproduction, cytogenetics and development," in Aphids, Their Biology, Natural Enemies, and Control, eds A. K. Minks and P. Harrewijin (Amsterdam: Elservier), 163-195.

Blackman, R. L., and Hales, D. F. (1986). Behaviour of the X chromosomes during growth and maturation of parthenogenetic eggs of Amphorophora tuberculata (Homoptera, Aphididae), in relation to sex determination. Chromosoma 94, 59-64. doi: 10.1007/BF00293530
Blomen, V. A., and Boonstra, J. (2011). Stable transmission of reversible modifications: maintenance of epigenetic information through the cell cycle. Cell. $\mathrm{Mol}$. Life Sci. 68, 27-44. doi: 10.1007/s00018-010-0505-5

Bollati, V., and Baccarelli, A. (2010). Environmental epigenetics. Heredity 105, 105-112. doi: 10.1038/hdy.2010.2

Braendle, C., Caillaud, M. C., and Stern, D. L. (2005a). Genetic mapping of aphicarus - a sex-linked locus controlling a wing polymorphism in the pea aphid (Acyrthosipon pisum). Heredity 94, 435-442. doi: 10.1038/sj.hdy.6800633

Braendle, C., Friebe, I., Caillaud, M. C., and Stern, D. L. (2005b). Genetic variation for an aphid wing polyphenism is genetically linked to a naturally occurring wing polymorphism. Proc. R. Soc. B 272, 657-664. doi: 10.1098/rspb.2004.2995

Braendle, C., Davis, G. K., Brisson, J. A., and Stern, D. L. (2006). Wing dimorphism in aphids. Heredity 97, 192-199. doi: 10.1038/sj.hdy.6800863

Brisson, J. A. (2010). Aphid wing dimorphisms: linking environmental and genetic control of trait variation. Phil. Trans. R. Soc. B 365, 605-616. doi: 10.1098/rstb.2009.0255

Brisson, J. A., Ishikawa, A., and Miura, T. (2010). Wing development genes of the pea aphid and differential gene expression between winged and unwinged morphs. Insect. Mol. Biol. 19, 63-73. doi: 10.1111/j.1365-2583.2009.00935.x

Caillaud, M. C., Boutin, M., Braendle, C., and Simon, J. C. (2002). A sex-linked locus controls wing polymorphism in males of the pea aphid, Acyrthosiphon pisum (Harris). Heredity 89, 346-352. doi: 10.1038/sj.hdy.6800146

Campbell, A., and Mackauer, M. (1977). Reproduction and population growth of the pea aphid (Homoptera: Aphididae) under laboratory and field conditions. Can. Entomol. 109, 277-284. doi: 10.4039/Ent109277-2

Colbourne, J. K., Pfrender, M. E., Gilbert, D., Thomas, W. K., Tucker, A., Oakley, T. H., et al. (2011). The ecoresponsive genome of Daphnia pulex. Science 331, 555-561. doi: 10.1126/science.1197761

Corbitt, T. S., and Hardie, J. (1985). Juvenile-hormone effects on polymorphism in the pea aphid, Acyrthosiphon pisum. Entomol. Exp. Appl. 38, 131-135. doi: 10.1111/j.1570-7458.1985.tb03509.x

Cortessis, V. K., Thomas, D. C., Levine, A. J., Breton, C. V., Mack, T. M., Siegmund, K. D., et al. (2012). Environmental epigenetics: prospects for studying epigenetic mediation of exposure-response relationships. Hum. Genet. 131, 1565-1589. doi: 10.1007/s00439-012-1189-8

Cortés, T., Tagu, D., Simon, J.-C., Moya, A., and Martínez-Torres, D. (2008). Sex versus parthenogenesis: a transcriptomic approach of photoperiod response in the model aphid Acyrthosiphon pisum (Hemiptera: Aphididae). Gene 408, 146-156. doi: 10.1016/j.gene.2007.10.030

Couchman, J. R., and King, P. E. (1980). Ovariole sheath structure and its relationship with developing embryos in a parthenogenetic viviparous aphid. Acta Zool. 61, 147-155. doi: 10.1111/j.1463-6395.1980.tb01302.x

Davis, G. K. (2012). Cyclical parthenogenesis and viviparity in aphids as evolutionary novelties. J. Exp. Zool. B Mol. Dev. Evol. 318, 448-459. doi: 10.1002/jez.b.22441

Dixon, A. F. G. (1972). The "interval timer," photoperiod and temperature in the seasonal development of parthenogenetic and sexual morphs in the lime aphid, Eucallipterus tiliae L. Oecologia 9, 301-310. doi: 10.1007/BF00345334

Dixon, A. F. G. (1998). Aphid Ecology. London: Chapman \& Hall.

Dixon, A. F. G., and Agarwala, B. K. (1999). Ladybird induced life historychanges in aphids. Proc. R. Soc. Lond. B 266, 1549-1553. doi: 10.1098/rspb.1999.0814

Dudley, R. (2002). The Biomechanics of Insect Flight: Form, Function, Evolution. Princeton: Princeton University Press.

Duncan, E. J., Leask, M. P., and Dearden, P. K. (2013). The pea aphid (Acyrthosiphon pisum) genome encodes two divergent early developmental programs. Dev. Biol. 377, 262-274. doi: 10.1016/j.ydbio.2013.01.036

El-Ziady, S., and Kennedy, J. S. (1956). Beneficial effects of the common garden ant, Lasius niger L., on the black bean aphid, Aphis fabae Scop. Proc. R. Entomol. Soc. Lond. 31, 61-65. doi: 10.1111/j.1365-3032.1956.tb00208.x

Feil, R., and Fraga, M. F. (2012). Epigenetics and the environment: emerging patterns and implications. Nat. Rev. Genet. 13, 97-109. doi: 10.1038/nrg3142

Forrest, J. M. S. (1970). The effect of maternal and larval experience on morph determination in Dysaphis devecta. J. Insect Physiol. 16, 2281-2292. doi: 10.1016/0022-1910(70)90151-4

Fukatsu, T. (2010). A fungal past to insect color. Science 328, 574-575. doi: $10.1126 /$ science. 1190417

Gao, N., and Hardie, J. (1996). Pre- and post-natal effects of precocenes on aphid morphogenesis and differential rescue. Arch. Ins. Bioch. Phys. 32, 503-510. doi: 10.1002/(SICI)1520-6327(1996)32:3/4,503::AID-ARCH22.3.0.CO;2-F 
Gao, N., and Hardie, J. (1997). Melatonin and the pea aphid, Acyrthosiphon pisum. J. Insect Physiol. 43, 615-620. doi: 10.1016/S0022-1910(97)00015-2

Gao, N., von Schantz, M., Foster, R. G., and Hardie, J. (1999). The putative brain photoperiodic photoreceptors in the vetch aphid, Megoura viciae. J. Insect Physiol. 45, 1011-1019. doi: 10.1016/S0022-1910(99)00082-7

International Aphid Genomics Consortium. (2010). Genome sequence of the pea aphid Acyrthosiphon pisum. PLoS Biol. 8:e1000313. doi: 10.1371/journal.pbio. 1000313

Granett, J., Walker, M. A., Kocsis, L., and Omer, A. D. (2001). Biology and management of grape phylloxerae. Annu. Rev. Entomol. 46, 387-412. doi: 10.1146/annurev.ento.46.1.387

Hall, B. K. (1999). Evolutionary Developmental Biology. Dordrecht: Kluwer. doi: 10.1007/978-94-011-3961-8

Hardie, J. (1990). The photoperiodic counter, quantitative day-length effects and scotophase timing in the vetch aphid Megoura viciae. J. Insect Physiol. 36, 939-949. doi: 10.1016/0022-1910(90)90082-Q

Hardie, J., Baker, F. C., Jamieson, G. C., Lees, A. D., and Schooley, D. A. (1985). The identification of an Aphid juvenile-hormone and its titer in relation to photoperiod. Physiol. Entomol. 10, 297-302. doi: 10.1111/j.1365-3032.1985. tb00050.x

Hardie, J., Gao, N., Timár, T., Sebók, P., and Honda, K. (1996). Precocene derivatives and aphid morphogenesis. Arch. Ins. Biochem. Physiol. 32, 493-501. doi: 10.1002/(SICI)1520-6327(1996)32:3/4,493::AID-ARCH21.3.0.CO;2-6

Hardie, J., and Nunes, M. V. (2001). Aphid photoperiodic clocks. J. Insect Physiol. 47, 821-832. doi: 10.1016/S0022-1910(01)00055-5

Harrison, R. G. (1980). Dispersal polymorphisms in insects. Annu. Rev. Ecol. Syst. 11, 95-118. doi: 10.1146/annurev.es.11.110180.000523

Hartfelder, K., and Engels, W. (1998). Social insect polymorphism: hormonal regulation of plascitiy in development and reproduction in the honeybee. Curr. Top. Dev. Biol. 40, 45-77. doi: 10.1016/S0070-2153(08)60364-6

Hatano, E., Baverstock, J., Kunert, G., Pell, J. K., and Weisser, W. W. (2012). Entomopathogenic fungi stimulate transgenerational wing induction in pea aphids, Acyrthosiphon pisum (Hemiptera: Aphididae). Ecol. Entomol. 37, 75-82. doi: 10.1111/j.1365-2311.2011.01336.x.

Hattori, M., Kishida, O., and Itino, T. (2013). Soldiers with large weapons in predator-abundant midsummer: reproductive plasticity in a eusocial aphid. Evol. Ecol. 27, 847-862. doi: 10.1007/s10682-012-9628-5

Havill, N. P., and Foottit, R. G. (2007). Biology and evolution of adelgidae. Annu. Rev. Entomol. 52, 325-349. doi: 10.1146/annurev.ento.52.110405.091303

Hazell, S. P., Gwynn, D. M., Ceccarelli, S., and Fellowes, M. D. E. (2005). Competition and dispersal in the pea aphid: clonal variation and correlations across traits. Ecol. Entomol. 30, 293-298. doi: 10.1111/j.0307-6946.2005. 00703.x

Heie, O. E. (1987). "Paleontology and phylogeny," in Aphids, Their Biology, Natural Enemies, and Control, eds A. K. Minks and P. Harrewijin (Amsterdam: Elservier), 367-391.

Hille Ris Lambers, L. (1966). Polymorphism in the aphididae. Annu. Rev. Entomol. 11, 47-78. doi: 10.1146/annurev.en.11.010166.000403

Huybrechts, J., Bonhomme, J., Minoli, S., Prunier-Leterme, N., Dombrovsky, A., Abdel-Latief, M., et al. (2010). Neuropeptide and neurohormone precursors in the pea aphid Acyrthosiphon pisum. Insect Mol. Biol. 19, 87-95. doi: 10.1111/j.1365-2583.2009.00951.x

Ishikawa, A., Gotoh, H., Abe, T., and Miura, T. (2013). Juvenile hormone titer and wing-morph differentiation in the vetch aphid Megoura crassicauda. J. Insect Physiol. 59, 444-449. doi: 10.1016/j.jinsphys.2013.02.004

Ishikawa, A., Hongo, S., and Miura, T. (2008). Morphological and histological examination of polyphenic wing formation in the pea aphid Acyrthosiphon pisum (Heteroptera, Hexapoda). Zoomorphology 127, 121-133. doi: 10.1007/s00435-008-0057-5

Ishikawa, A., and Miura, T. (2007). Morphological differences between wing morphs of two Macrosiphini aphid species, Acyrthosiphon pisum and Megoura crassicauda (Hemiptera, Aphididae). Sociobiology 50, 881-893.

Ishikawa, A., and Miura, T. (2013). Transduction of high-density signals across generations in aphid wing polyphenism. Physiol. Entomol. 38, 150-156. doi: 10.1111/phen. 12022

Ishikawa, A., Ogawa, K., Gotoh, H., Walsh, T. K., Tagu, D., Brisson, J. A., et al. (2012). Juvenile hormone titer and gene expression during the change of reproductive modes in the pea aphid. Insect Mol. Biol. 12, 49-60. doi: 10.1111/j.1365-2583.2011.01111.x
Itô, Y. (1989). The evolutionary biology of sterile soldiers in aphids. Trends Ecol. Evol. 4, 69-73. doi: 10.1016/0169-5347(89)90151-1

Jaubert-Possamai, S., Le Trionnaire, G., Bonhomme, J., Christophides, G. K., Rispe, C., and Tagu, D. (2007). Gene knockdown by RNAi in the pea aphid Acyrthosiphon pisum. BMC Biotechnol. 7:63. doi: 10.1186/1472-6750-7-63

Johnson, B. (1965). Wing polymorphism in aphids-II. Interaction between aphids. Ent. Exp. Appl. 8, 49-64. doi: 10.1007/BF00304538

Johnson, B., and Birks, P. R. (1960). Studies on wing polymorphism in aphids I. The developmental process involved in the production of the different forms. Entomol. Exp. Appl. 3, 327-339. doi: 10.1111/j.1570-7458.1960. tb00461.x

Kalmus, H. (1945). Correlations between flight and vision, and particularly between wings and ocelli, in insects. Proc. R. Entomol. Soc. Lond. A 20, 84-96. doi: 10.1111/j.1365-3032.1945.tb01072.x

Kawada, K. (1987). "Polymorphism and morph determination," in Aphids, Their Biology, Natural Enemies, and Control, eds A. K. Minks and P. Harrewijin (Amsterdam: Elservier), 255-266.

Kenten, J. (1955). The effect of photoperiod and temperature on reproduction in Acyrthosiphon pisum (Harris) and on the forms produced. Bull. Entomol. Res. 46, 599-624. doi: 10.1017/S0007485300039572

Kleinjan, J. E., and Mittler, T. E. (1975). A chemical influence of ants on wing development in aphids. Entomol. Exp. Appl. 18, 384-388. doi: 10.1111/j.15707458.1975.tb00411.x

Kring, J. B. (1977). Structure of the eyes of the pea aphid, Acyrthosiphon pisum. Ann. Entomol. Soc. Am. 70, 855-860.

Kunert, G., Otto, S., Rose, U. S. R., Gershenzon, J., and Weisser, W. W. (2005). Alarm pheromone mediates production of winged dispersal morphs in aphids. Ecol. Lett. 8, 596-603. doi: 10.1111/j.1461-0248.2005.00754.x

Kunert, G., Schmook-Ortlepp, K., Reissmann, U., and Weisser, W. W. (2008). The influence of natural enemies on wing induction in Aphis fabae and Megoura viciae (Hemiptera, Aphididae). Bull. Entomol. Res. 98, 57-62. doi: 10.1017/S0007485307005391

Kunert, G., and Weisser, W. W. (2003). The interplay between density- and traitmediated effects in predator-prey interactions: a case study in aphid wing polymorphism. Oecologia 135, 304-312. doi: 10.1007/s00442-003-1185-8

Kurosu, U., and Aoki, S. (2009). Extremely long-closed galls of a social aphid. Psyche 2009, 159478. doi: 10.1155/2009/159478

Lamb, R. J., and MacKay, P. A. (1979). Variability in migratory tendency within and among natural populations of the pea aphid, Acyrthosiphon pisum. Oecologia 39, 289-299. doi: 10.1007/BF00345440

Lamb, R. J., and Pointing, P. J. (1972). Sexual morph determination in the aphid, Acyrthosiphon pisum. J. Insect Physiol. 18, 2029-2042. doi: 10.1016/00221910(72)90170-9

Lees, A. D. (1959). The role of photoperiod and temperature in the determination of parthenogenetic and sexual forms in the aphid Megoura viciae Buckton. I. The influence of these factors on apterous virginoparae and their progeny. $J$. Insect Physiol. 3, 92-117. doi: 10.1016/0022-1910(59)90024-1

Lees, A. D. (1960). The role of photoperiod and temperature in the determination of parthenogenetic and sexual forms in the aphid Megoura viciae Buckton. II. The operation of the "interval timer" in young clones. J. Insect Physiol. 4, 154-175. doi: 10.1016/0022-1910(60)90078-0

Lees, A. D. (1963). The role of photoperiod and temperature in the determination of parthenogenetic and sexual forms in the aphid Megoura viciae Buckton. III. Further properties of the maternal switching mechanism in apterous aphids. $J$. Insect Physiol. 9, 153-164. doi: 10.1016/0022-1910(63)90067-2

Lees, A. D. (1964). The Location of the photoperiodic receptors in the aphid Megoura viciae Buckton. J. Exp. Biol. 41, 119-133.

Lees, A. D. (1966). The control of polymorphism in aphids. Adv. Insect Physiol. 3 , 207-277. doi: 10.1016/S0065-2806(08)60188-5

Lees, A. D. (1967). The production of the apterous and alate forms in the aphid Megoura viciae Buckton, with special reference to the role of crowding. J. Insect Physiol. 13, 289-318. doi: 10.1016/0022-1910(67)90155-2

Leonardo, T. E., and Mondor, E. B. (2006). Symbiont modifies host lifehistory traits that affect gene flow. Proc. R. Soc. B Biol. 273, 1079-1084. doi: 10.1098/rspb.2005.3408

Le Trionnaire, G., Francis, F., Jaubert-Possamai, S., Bonhomme, J., De Pauw, E., Gauthier, J. P., et al. (2009). Transcriptomic and proteomic analyses of seasonal photoperiodism in the pea aphid. BMC Genomics 10:456. doi: 10.1186/14712164-10-456 
Le Trionnaire, G., Hardie, J., Jaubert-Possamai, S., Simon, J.-C., and Tagu, D. (2008). Shifting from clonal to sexual reproduction in aphids: physiological and developmental aspects. Biol. Cell 100, 441-451. doi: 10.1042/ BC20070135

Lu, H. L., Tanguy, S., Rispe, C., Gauthier, J. P., Walsh, T., Gordon, K., et al. (2011). Expansion of genes encoding piRNA-associated argonaute proteins in the pea aphid: diversification of expression profiles in different plastic morph. PLoS ONE 6:e28051. doi: 10.1371/journal.pone.0028051

Lyko, F., and Maleszka, R. (2011). Insects as innovative models for functional studies of DNA methylation. Trends Genet. 27, 127-131. doi: 10.1016/j.tig.2011.01.003

MacKay, P. A., and Lamb, R. J. (1979). Migratory tendency in aging populations of the pea aphid, Acyrthosiphon pisum. Oecologia 39, 301-308. doi: 10.1007/BF00345441

MacKay, P. A., and Wellington, W. G. (1975). A comparison of the reproductive patterns of apterous and alate virginoparous Acyrthosiphon pisum (Homoptera: Aphididae). Can. Entomol. 107, 1161-1166. doi: 10.4039/Ent1071161-11

Mackay, P. A., and Wellington, W. G. (1977). Maternal age as a source of variation in the ability of an aphid to produce dispersing forms. Res. Popul. Ecol. 18, 195-209. doi: 10.1007/BF02754093

Mao, J., and Zeng, F. (2012). Feeding-based RNA interference of a gap gene is lethal to the pea aphid, Acyrthosiphon pisum. PLoS ONE 7:e48718. doi: 10.1371/journal.pone.0048718

Marcovitch, S. (1923). Plant lice and light exposure. Science 58, 537-538. doi: $10.1126 /$ science.58.1513.537-a

Marcovitch, S. (1924). The migration of the aphididae and the appearance of the sexual forms as affected by the relative length of daily light exposure. J. Agric. Res. 27, 513-522.

Maynard Smith, J. (1978). The Evolution of Sex. Cambridge: Cambridge University Press.

Mittler, T. E., and Sutherland, O. R. W. (1969). Dietary influences on aphid polymorphism. Entomol. Exp. Appl. 12, 703-713. doi: 10.1111/j.15707458.1969.tb02563.x

Miyazaki, M. (1987). "Forms and Morphs of aphids," in Aphids, Their Biology, Natural Enemies, and Control, eds A. K. Minks and P. Harrewijin (Amsterdam: Elservier), 27-50.

Moran, N. A. (1992). The evolution of aphid life cycles. Annu. Rev. Entomol. 37, 321-348. doi: 10.1146/annurev.en.37.010192.001541

Morgan, T. H. (1906). The male and female eggs of phylloxerans of the hickories. Biol. Bull. 10, 201-206. doi: 10.2307/1535539

Morgan, T. H. (1908). The production of two kinds of spermatozoa in phylloxerans - functional "female producing" and rudimentary spermatozoa. Soc. Exp. Biol. Med. Proc. 5, 56-57. doi: 10.3181/00379727-5-30

Morgan, T. H. (1909a). A biological and cytological study of sex determination in phylloxerans and aphids. J. Exp. Zool. 7, 239-351. doi: 10.1002/jez.1400070203

Morgan, T. H. (1909b). Sex determination and parthenogenesis in phylloxerans and aphids. Science 29, 234-237. doi: 10.1126/science.29.736.234

Morgan, T. H. (1912). The elimination of the sex chromosomes from the male-producing eggs of phylloxerans. J. Exp. Zool. 12, 479-498. doi: 10.1002/jez.1400120403

Morgan, T. H. (1915). The predetermination of sex in phylloxerans and aphids. J. Exp. Zool. 19, 285-321. doi: 10.1002/jez.1400190303

Moritsu, M. (1983). Nihon Genshoku Aburamushi Zukan (in Japanese). Tokyo: Zenkoku Noson Kyoiku Kyokai.

Müller, C. B., Williams, I. S., and Hardie, J. (2001). The role of nutrition, crowding and interspecific interactions in the development of winged aphids. Ecol. Entomol. 26, 330-340. doi: 10.1046/j.1365-2311.2001.00321.x

Mutti, N. S., Park, Y., Reese, J. C., and Reeck, G. R. (2006). RNAi knockdown of a salivary transcript leading to lethality in the pea aphid, Acyrthosiphon pisum. J. Insect Sci. 6, 1-7. doi: 10.1673/031.006.3801

Nijhout, H. F. (1999). Control mechanisms of phenotypic development in insects. Bioscience 49, 181-192. doi: 10.2307/1313508

Nijhout, H. F. (2003). Development and evolution of adaptive polyphenisms. Evol. Dev. 5, 9-18. doi: 10.1046/j.1525-142X.2003.03003.x

Noda, I. (1960). The emergence of winged viviparous female in aphid. -VI. Difference in rate of development between the winged and unwinged forms. Jap. J. Appl Entomol. Zool. 10, 97-102.

Ogawa, K., Ishikawa, A., Kanbe, T., Akimoto, S., and Miura, T. (2012). Male-specific flight apparatus development in Acyrthosiphon pisum (Aphididae, Hemiptera,
Insecta): comparison with female wing polyphenism. Zoomorphology 131, 197-207. doi: 10.1007/s00435-012-0154-3

Ogawa, K., and Miura, T. (2013). Two developmental switch points for the wing polymorphismses of the flight-apparatus in the pea aphid, Acyrthosiphon pisum. Evodevo 4, 30. doi:10.1186/2041-9139-4-30

Orlando, E. (1974). Sex determination in Megoura viciae Buckton (Homoptera, Aphididae). Monitore Zool. Italiano 8, 61-70. doi: 10.1080/00269786.1974.10736224

Orlando, E. (1983). Chromosomal abnormalities in males-producing eggs: a study in Megoura viciae (Homoptera, Aphididae). Genetica 62, 55-59. doi: 10.1007/BF00123311

Parthasarathy, R., Tan, A., and Palli, S. R. (2008). bHLH-PAS family transcription factor methoprene-tolerant plays a key role in $\mathrm{JH}$ action in preventing the premature development of adult structures during larval-pupal metamorphosis. Mech. Dev. 125, 601-616. doi: 10.1016/j.mod.2008.03.004

Pitino, M., Coleman, A. D., Maffei, M. E., Ridout, C. J., and Hogenhout, S. A. (2011). Silencing of aphid genes by dsRNA feeding from plants. PLoS ONE 6:e25709. doi: 10.1371/journal.pone.0025709

Price, D. R. G., Duncan, R. P., Shigenobu, S., and Wilson, A. C. C. (2011). Genome expansion and differential expression of amino acid transporters at the aphid/Buchnera symbiotic interface. Mol. Biol. Evol. 28, 3113-3126. doi: 10.1093/molbev/msr140

Pursley, S., Ashok, M., and Wilson, T. G. (2000). Intracellular localization and tissue specificity of the Methoprene-tolerant $(\mathrm{Met})$ gene product in Drosophila melanogaster. Insect Biochem. Mol. Biol. 30, 839-845. doi: 10.1016/S09651748(00)00056-4

Ramos, S., Moya, A., and Martínez-Torres, D. (2003). Identification of a gene overexpressed in aphids reared under short photoperiod. Insect Biochem. Mol. Biol. 33, 289-298. doi: 10.1016/S0965-1748(02)00243-6

Riparbelli, M. G., Tagu, D., Bonhomme, J., and Callaini, G. (2005). Aster selforganization at meiosis: a conserved mechanism in insect parthenogenesis? Dev. Biol. 278, 220-230. doi: 10.1016/j.ydbio.2004.11.009

Rispe, C., and Pierre, J. S. (1998). Coexistence between cyclical parthenogens, obligate parthenogens, and intermediates in a fluctuating environment. J. Theor. Biol. 195, 97-110. doi: 10.1006/jtbi.1998.0784

Rispe, C., Pierre, J.-S., Simon, J.-C., and Gouyon, P.-H. (1998). Models of sexual and asexual coexistence in aphids based on constraints. J. Evol. Biol. 11, 685-701. doi: 10.1046/j.1420-9101.1998.11060685.x

Rodrigues-Martins, A., Riparbelli, M., Callaini, G., Glover, D. M., and BettencourtDias, M. (2007). Revisiting the role of the mother centriole in centriole biogenesis. Science 316, 1046-1050. doi: 10.1126/science.1142950

Roff, D. A. (1990). The evolution of flightlessness in insects. Ecol. Monogr. 60, 389-421. doi: 10.2307/1943013

Roff, D. A., and Fairbairn, D. J. (1991). Wing dimorphisms and the evolution of migratory polymorphisms among the Insecta. Am. Zool. 31, 243-251. doi: 10.1093/icb/31.1.243

Shigenobu, S., Bickel, R. D., Brisson, J. A., Butts, T., Chang, C. C., Christiaens, O., et al. (2010). Comprehensive survey of developmental genes in the pea aphid, Acyrthosiphon pisum: frequent lineage-specific duplications and losses of developmental genes. Insect Mol. Biol. 19(Suppl. 2), 47-62. doi: 10.1111/j.13652583.2009.00944.x

Schaefers, G. A., and Judge, F. D. (1971). Effects of temperature, photoperiod, and host plant on alary polymorphism in the aphid, Chaetosiphon fragaefolii. J. Insect Physiol. 17, 365-379. doi: 10.1016/0022-1910(71)90220-4

Schön, I., Martens, K., and van Dijk, P. (2009). Lost Sex: The Evolutionary Biology of Parthenogenesis. Dordrecht: Springer doi: 10.1007/978-90-481-2770-2

Schwartzberg, E. G., Kunert, G., Westerlund, S. A., Hoffmann, K. H., and Weisser, W. W. (2008). Juvenile hormone titres and winged offspring production do not correlate in the pea aphid, Acyrthosiphon pisum. J. Insect Physiol. 54, 1332-1336. doi: 10.1016/j.jinsphys.2008.04.025

Shaw, M. J. P. (1970). Effect of population density on alienocolae of Aphis fabae Scop. I. The effect of crowding on the production of alatae in the laboratory. Ann. Appl. Biol. 65, 191-196. doi: 10.1111/j.1744-7348.1970.tb04578.x

Shibao, H., Kutsukake, M., Matsuyama, S., Fukatsu, T., and Shimada, M. (2010). Mechanisms regulating caste differentiation in an aphid social system. Commun. Integr. Biol. 3, 1-5. doi: 10.4161/cib.3.1.9694

Sim, C., and Denlinger, D. L. (2008). Insulin signaling and FOXO regulate the overwintering diapause of the mosquito Culex pipiens. Proc. Natl. Acad. Sci. U.S.A. 105, 6777-6781. doi: 10.1073/pnas.0802067105 
Simon, J.-C., Martinez-Torres, D., Latorre, A., Moya, A., and Hebert, P. D. (1996) Molecular characterization of cyclic and obligate parthenogens in the aphid Rhopalosiphum padi (L.). Proc. Biol. Sci. 263, 481-486. doi: 10.1098/rspb.1996.0072

Simon, J.-C., Rispe, C., and Sunnucks, P. (2002). Ecology and evolution of sex in aphids. Trends Ecol. Evol. 17, 34-39. doi: 10.1016/S0169-5347(01)02331-X

Simon, J.-C., Stoeckel, S., and Tagu, D. (2010). Evolutionary and functional insights into reproductive strategies of aphids. C. R. Biol. 333, 488-496. doi: 10.1016/j.crvi.2010.03.003

Sloane, M. A., Sunnucks, P., Wilson, A. C., and Hales, D. F. (2001). Microsatellite isolation, linkage group identification and determination of recombination frequency in the peach-potato aphid, Myzus persicae (Sulzer) (Hemiptera: Aphididae). Genet. Res. 77, 251-60. doi: 10.1017/S0016672301005018

Sloggett, J. J., and Weisser, W. W. (2002). Parasitoids induce production of the dispersal morph of the pea aphid, Acyrthosiphon pisum. Oikos 98, 323-333. doi: 10.1034/j.1600-0706.2002.980213.x

Smith, M. A. H., and MacKay, P. A. (1989). Genetic variation in male alary dimorphism in populations of pea aphid, Acyrthosiphon pisum. Entomol. Exp. Appl. 51, 125-132. doi: 10.1111/j.1570-7458.1989.tb01222.x

Smith, M. A. H., and MacKay, P. A. (1990). Latitudinal variation in the photoperiodic responses of populations of pea aphid (Homoptera: Aphididae). Environ. Entomol. 19, 618-624.

Srinivasan, D. G., and Brisson, J. A. (2012). Aphids: a model for polyphenism and epigenetics. Genet. Res. Int. 2012:431531. doi: 10.1155/2012/431531

Srinivasan, D. G., Fenton, B., Jaubert-Possamai, S., and Jaouannet, M. (2010). Analysis of meiosis and cell cycle genes of the facultatively asexual pea aphid, Acyrthosiphon pisum (Hemiptera: Aphididae). Insect Mol. Biol. 19(Suppl. 2), 229-239. doi: 10.1111/j.1365-2583.2009.00960.x

Steel, C. G. H., and Lees, A. D. (1977). Role of neurosecretion in photoperiodic control of polymorphism in the aphid Megoura viciae. J. Exp. Biol. 67, 117-135.

Steffan, A. W. (1970). Eidonomic and cytological studies on anholocyclicparthenogenetic species of Adelgidae Homoptera: Aphidina. Zeitschrift für Angewandte Entomol. 65, 444-452. doi: 10.1111/j.1439-0418.1970.tb04008.x

Stern, D. L., and Foster, W. A. (1996). The evolution of soldiers in aphids. Biol. Rev. Camb. Philos. Soc. 71, 27-79. doi: 10.1111/j.1469-185X.1996.tb00741.x

Stevens, N. M. (1905). A study of the germ cells of Aphis rosae and Aphis oenotherae. J. Exp. Zool. 2, 313-333. doi: 10.1002/jez.1400020302

Stevens, N. M. (1906). Studies on the Germ Cell of Aphids. Carnegie; Washington: Institution of Washington. doi: 10.5962/bhl.title.23657

Stevens, N. M. (1910). A note on reduction in the maturation of male eggs in Aphis. Biol. Bull. 18, 72-75. doi: 10.2307/1535909

Sutherland, O. R. W. (1969a). The role of crowding in the production of winged forms by two strains of the pea aphid, Acyrthosiphon pisum. J. Insect Physiol. 15, 1385-1410. doi: 10.1016/0022-1910(69)90199-1

Sutherland, O. R. W. (1969b). The rôle of the host plant in the production of winged forms by two strains of the pea aphid, Acyrthosiphon pisum. J. Insect Physiol. 15, 2179-2201. doi: 10.1016/0022-1910(69)90083-3

Sutherland, O. R. W. (1970). An intrinsic factor influencing the alate production by two strains of the pea aphid, Acyrthosiphon pisum. J. Insect Physiol. 16, 1349-1354. doi: 10.1016/0022-1910(70)90134-4

Sutherland, O. R. W., and Mittler, T. E. (1971). Influence of diet composition and crowding on wing production by aphid Myzus persicae. J. Insect Physiol. 17, 321-328. doi: 10.1016/0022-1910(71)90216-2

Toba, H. H., Paschke, J. D., and Friedman, S. (1967). Crowding as the primary factor in the production of the agamic alate form of Therioaphis maculata (Homoptera: Aphididae). J. Insect Physiol. 13, 381-396. doi: 10.1016/00221910(67)90079-0

Tsuchida, T., Koga, R., Horikawa, M., Tsunoda, T., Maoka, T., Matsumoto, S., et al. (2010). Symbiotic bacterium modifies aphid body color. Science 330, 1102-1104. doi: 10.1126/science.1195463

Tsuji, H., and Kawada, K. (1987a). Development and degeneration of wing buds and indirect flight muscle in the pea aphid (Acyrthosiphon pisum (Harris)). Jpn. J. Appl. Ent. Zool. 31, 247-252. doi: 10.1303/jjaez.31.247
Tsuji, H., and Kawada, K. (1987b). Effects of starvation on life span and embryo development of four morphs of pea aphid (Acyrthosiphon pisum (Harris). Jpn. J. Appl. Ent. Zool. 31, 36-40. doi: 10.1303/jjaez.31.36

Tsumuki, H., Nagatsuka, H., Kawada, K., and Kanehisa, K. (1990). Comparison of nutrient reservation in apterous and alate pea aphids, Acyrthosiphon pisum (Harris). 1. Developmental time and sugar content. Appl. Entomol. Zool. 25, 215-221.

Tu, M. P., Yin, C. M., and Tatar, M. (2005). Mutations in insulin signaling pathway alter juvenile hormone synthesis in Drosophila melanogaster. Gen. Comp. Endocrinol. 142, 347-356. doi: 10.1016/j.ygcen.2005.02.009

Wagner, D. L., and Liebherr, J. K. (1992). Flightlessness in insects. Trends Ecol. Evol. 7, 216-220. doi: 10.1016/0169-5347(92)90047-F

Walsh, T. K., Brisson, J. A., Robertson, H. M., Gordon, K., Jaubert-Possamai, S., Tagu, D., et al. (2010). A functional DNA methylation system in the pea aphid, Acyrthosiphon pisum. Insect Mol. Biol.19(Suppl. 2), 215-228. doi: 10.1111/j.1365-2583.2009.00974.x

Watanabe, T., Ochiai, H., Sakuma, T., Horch, H. W., Hamaguchi, N., Nakamura, T., et al. (2012). Non-transgenic genome modifications in a hemimetabolous insect using zinc-finger and TAL effector nucleases. Nat. Commun. 3, 1017. doi: 10.1038/ncomms 2020

Weisser, W. W., Braendle, C., and Minoretti, N. (1999). Predator-induced morphological shift in the pea aphid. Proc. R. Soc. Lond. B 266, 1175-1181. doi: 10.1098/rspb.1999.0760

West-Eberhard, M. J. (2003). Developmental Plasticity and Evolution. Oxford: Oxford University Press.

White, W. S. (1946). The environmental conditions affecting the genetic mechanism of wing production in the chrysanthemum aphid. Am. Nat. 80, 245-270. doi: $10.1086 / 281430$

Williams, G. C. (1975). Sex and Evolution. Princeton: Princeton University Press.

Wilson, A. C. C., Sunnucks, P., and Hales, D. F. (1997). Random loss of X chromosome at male determination in an aphid, Sitobion near fragariae, detected using an X-linked polymorphic microsatellite marker. Genet. Res. 69, 233-236. doi: 10.1017/S0016672397002747

Yao, I. (2012). Ant attendance reduces flight muscle and wing size in the aphid Tuberculatus quercicola. Biol. Lett. 8, 624-627. doi: 10.1098/rsbl.2012.0014

Zera, A. J. (2003). The endocrine regulation of wing polymorphism in insects: state of the art, recent surprises, and future directions. Integr. Comp. Biol. 43, 607-616. doi: 10.1093/icb/43.5.607

Zera, A. J., and Denno, R. F. (1997). Physiology and ecology of dispersal polymorphism in insects. Annu. Rev. Entomol. 42, 207-230. doi: 10.1146/annurev.ento.42.1.207

Zera, A. J., Strambi, C., Tiebel, K. C., Strambi, A., and Rankin, M. A. (1989). Juvenile hormone and ecdysteroid titers during critical periods of wing morph determination in Gryllus rubens. J. Insect Physiol. 35, 501-511. doi: 10.1016/0022-1910(89)90057-7

Conflict of Interest Statement: The authors declare that the research was conducted in the absence of any commercial or financial relationships that could be construed as a potential conflict of interest.

Received: 30 October 2013; paper pending published: 10 December 2013; accepted: 01 January 2014; published online: 24 January 2014.

Citation: Ogawa K and Miura T (2014) Aphid polyphenisms: trans-generational developmental regulation through viviparity. Front. Physiol. 5:1. doi: 10.3389/fphys. 2014.00001

This article was submitted to Integrative Physiology, a section of the journal Frontiers in Physiology.

Copyright (c) 2014 Ogawa and Miura. This is an open-access article distributed under the terms of the Creative Commons Attribution License (CC BY). The use, distribution or reproduction in other forums is permitted, provided the original author(s) or licensor are credited and that the original publication in this journal is cited, in accordance with accepted academic practice. No use, distribution or reproduction is permitted which does not comply with these terms. 